\title{
Quality of marital life in Korean spinal cord injured patients
}

\author{
Shin Young Yim ${ }^{1}$, Il Yung Lee ${ }^{1}$, Seung Hyun Yoon ${ }^{1}$, Mi Sook Song ${ }^{2}$, Eun Woo Rah ${ }^{1}$ and Hae Won Moon ${ }^{1}$ \\ ${ }^{1}$ Department of Physical Medicine and Rehabilitation, ${ }^{2}$ Department of Preventive Medicine and Public Health, Ajou \\ University School of Medicine, Suwon, Korea
}

\begin{abstract}
The purposes of this study were to assess the quality of marital life and to investigate the most serious problem in the marital relationships of Korean spinal cord injured patients. 30 spinal cord injured (SCI) couples (SCI husbands and their non-disabled wives) who were married prior to injury and 30 able-bodied $(\mathrm{AB})$ couples participated in a questionnaire study. The quality of marital life was measured with three parameters: marital stability, marital adjustment, and marital satisfaction. The results were as follows: (1) The marriage of chronic SCI couples was not noticeably unstable when compared with that of AB couples; (2) There was no significant difference in dyadic adjustment and marital satisfaction between SCI couples and $\mathrm{AB}$ couples; (3) There was no significant difference in marital stability, marital adjustment, and marital satisfaction between SCI husbands and their wives; (4) SCI couples had more cohesive marital relationships and SCI husbands expressed less affection to their wives than $\mathrm{AB}$ husbands and (5) Sex was the most serious problem in marriages of SCI couples. In conclusion: (1) the quality of marital life in chronic SCI couples is not highly different from that of $\mathrm{AB}$ couples; (2) There is no significant difference in the quality of marital life between chronic SCI husbands and their non-disabled wives; and (3) It is considered necessary that rehabilitation program for SCI patients should include information on the altered physiology of sexual function of SCI patients and subsequent mutual adaptation to changed sexual function.
\end{abstract}

Keywords: Quality of marital life; spinal cord injured couples; marital stability; marital adjustment; marital satisfaction

\section{Introduction}

An irreversible traumatic spinal cord injury (SCI) is one of the most serious events that can happen in a person's life. It is natural to assume that when one of the partners incurs a SCI, a tremendous strain will be placed on a marriage. A number of the direct or indirect consequences of SCI are known to be stressors for both spouses and for marriage. These include the injured partner's limited capacity to fulfil household and child care tasks; his or her care needs; reduced mobility resulting in reduction of outings and social contacts; financial pressures and a lowered standard of living; changes in sexual functioning; job loss and the subsequent loss of social status; assumption of the stigmatized disabled status; and psychological adjustment problems. ${ }^{1,2}$ The adjustment requires significant strength on the part of the injured person and much effort from people close to him or her, as well as from society. Most persons succeed during the subsequent years in finding a new life with possibilities of realizing the

Correspondence: SY Yim, Department of Physical Medicine and Rehabilitation, Ajou University School of Medicine, San 5, Wonchon-dong, Paldal-ku, Suwon, Korea, 442-749 quality of life towards which they aim. ${ }^{2}$ Stensman $^{3}$ stated $64.4 \%$ of traumatic SCI patients reported good adjustment and high quality of life after the injury.

Since the quality of marital relationship among SCI patients influences their rehabilitational outcome and quality of life, ${ }^{4}$ surveys on the quality of marital relationships of SCI couples and efforts to identify and improve the most problematic area of marriage among SCI couples are important. Therefore, the purposes of this study were to assess the quality of marital life and to investigate the most serious problem in marital relationships in SCI couples, and ultimately to provide the basic information for the development of rehabilitation programs for SCI patients.

\section{Methods}

\section{Subjects}

Each patient group was composed of thirty SCI couples (traumatic SCI husbands and their nondisabled wives) who were married prior to injury. The inclusion criterion consisted of SCI couples who 
had lived at home at least 6 months or more after their husbands' initial rehabilitation hospitalization for SCI. The mean duration of husbands' SCI was $2.71 \pm 2.11$ years (range $1-8$ years). Eighteen husbands were quadriplegic and 12 paraplegic. The distribution according to ASIA Impairment Scale showed 11A $(36.7 \%)$, 5B (16.7\%), 11C (36.7\%), and $3 \mathrm{D}(10 \%)$. The control group was composed of 30 able-bodied (AB) couples whose age, income, and educational levels were matched with patient group. Demographic characteristics of subjects are presented in Table 1. There was no significant difference in the demographic characteristics between AB couples and SCI couples. The mean monthly family income was about 1,565,000 won (about 1,565 dollars) in SCI couples and 1,602,600 won (about 1,603 dollars) in AB couples, and the subjects represented relatively low-income brackets in Korea. Eight SCI husbands $(27 \%)$ were employed, twenty-seven AB husbands $(90 \%)$ were employed. We conducted a questionnaire survey for marital stability, marital adjustment, and marital satisfaction in order to measure the quality of marital life between the two groups.

For the couples who participated in this questionnaire survey at our hospital, we separated spouses from each other when answering the questions. For the couples who did not visit our hospital, the questionnaire was delivered to their home. The participants were asked to answer the questions in a state of privacy from their spouse. For SCI husbands with poor hand functions and no ability to independently answer the questions, we had a third person assist the SCI husbands.

\section{Measurement instruments}

Marital stability Short Marital Instability Scale ${ }^{5,6}$ was used to measure marital stability, where lower score represented higher marital stability. This is a powerful indicator of marital instability and could be used as a single-item indicator. This scale is composed of five questions originally selected from Marital Instability Scale. $^{6}$

Marital adjustment Marital adjustment was measured with the modified Dyadic Adjustment Scale. The Dyadic Adjustment Scale $^{7}$ is a paper-and-pencil test, which was designed as an assessment tool for measuring the quality of adjustment in marriage. Originally, this scale was a 32-question scale with four subscales (13 dyadic consensus, 10 dyadic satisfaction, five dyadic cohesion, and four affectional expression). From the original scale, we excluded 10 questions of dyadic satisfaction due to the overlapping of Short Marital Instability Scale and seven questions that were thought to be irrelevant according to the standards of Korean culture. Dyadic Adjustment Scale originally used a 0-1, $0-4,0-5$ and $0-6$ scoring system, depending on the nature of the questions. We modified this scoring system as $0-10,0-5$ and $0-1$ system, because the participants in our pilot study replied that the original scoring system, translated into Korean and was hard to understand the exact meaning and needed to be modified. Finally, we used a 15-question modified Dyadic Adjustment Scale (eight dyadic consensus, three dyadic cohesion, and four affectional expression) with a $0-10,0-5$ and $0-1$ scoring system, once again depending on the nature of questions.

Marital satisfaction Marital satisfaction was measured with the Marital Agendas Protocol. ${ }^{8}$ The Marital Agendas Protocol is a four-section questionnaire that significantly correlates with measures of marital satisfaction. Each section contains 10 'agendas' that record the problem areas of the marriage, the level of agreement about the seriousness of the problems (problem intensity score), the expectation among the partners that the problems can be resolved, and whom

Table 1 Demographic characteristics of subjects

\begin{tabular}{lcc}
\hline Characteristics & AB* group $(\mathrm{n}=30)$ & SCI group $(\mathrm{n}=30)^{*}$ \\
\hline Age (year-old) & & $39.80 \pm 9.26$ \\
$\quad$ Husband & $40.15 \pm 3.91$ & $26.46 \pm 8.14$ \\
$\quad$ Wife & $36.75 \pm 3.75$ & $12.90 \pm 9.89$ \\
Number of years married (years) & $13.08 \pm 3.43$ & $1602600 \pm 979900$ \\
Monthly family income (won) & $1565000 \pm 369700$ & $1603 \pm 980$ \\
Monthly family income (dollars) & $1565 \pm 370$ & $12.70 \pm 3.11$ \\
Years of education (years) & $12.30 \pm 1.72$ & $11.30 \pm 2.25$ \\
$\quad$ Husband & $11.90 \pm 1.94$ & $1.85 \pm 1.10$ \\
$\quad$ Wife & $1.90 \pm 0.30$ & \\
Number of children & & \\
\hline
\end{tabular}

* Able-bodied couples. $†$ Spinal cord injured couples 
each partner blames for continued conflict. In this study, we used the problem intensity score in measuring the outcome.

\section{Statistical analysis}

For the statistical analyses of these data, an independent T-test was used for group comparison (SCI group versus $\mathrm{AB}$ group and husbands versus wives).

Table 2 Short marital instability scale in $\mathrm{AB}^{*}$ and $\mathrm{SCI} \dagger$ couples

\begin{tabular}{lccc}
\hline Scale & $\begin{array}{c}\text { AB } \\
\text { group }\end{array}$ & $\begin{array}{c}\text { SCI } \\
\text { group }\end{array}$ & $\begin{array}{c}\mathrm{P} \\
\text { value }\end{array}$ \\
\hline $\begin{array}{l}\text { Short marital } \\
\text { instability scale } \ddagger\end{array}$ & $2.30 \pm 3.24$ & $0.79 \pm 1.51$ & 0.011 \\
$\quad$ Husband $(n=30)$ & $1.95 \pm 3.03$ & $1.06 \pm 1.78$ & $>0.05$ \\
Wife $(n=30)$ & $2.65 \pm 3.47$ & $0.53 \pm 1.18$ & 0.017 \\
\hline
\end{tabular}

$*$ Able-bodied couples. $†$ Spinal cord injured couples. $\$$ No difference between husbands and wives in both $\mathrm{AB}$ group $(P=0.501)$ and SCI group $(P=0.315)$ for short marital instability scale

\section{Results}

Marital stability

Short Marital Instability Scale is presented in Table 2. Short Marital Instability Scale was 2.30 in the AB group and 0.79 in the SCI group. Marital stability was significantly higher in SCI group $(P=0.011)$, mainly attributed to the wives among the SCI group who reported significantly higher marital stability than those in AB group $(P=0.017)$. No difference between husbands and wives in both $\mathrm{AB}$ group $(P=0.501)$ and SCI group $(P=0.315)$ for short marital instability scale.

\section{Marital adjustment}

There was no significant difference of total Dyadic Adjustment Scale between the two groups (Table 3). But the SCI group showed a significantly higher dyadic cohesion subscale than AB group $(P=0.003)$. And the SCI group showed lower affectional expression subscale than $\mathrm{AB}$ group; this was mainly attributed to the husbands in SCI group who reported less affectional expression to their wives than those in $A B$ group $(P=0.013)$. There was no difference between

Table 3 Dyadic adjustment scale in $\mathrm{AB}^{*}$ and $\mathrm{SCI} \uparrow$ couples

\begin{tabular}{|c|c|c|c|}
\hline Scale & $A B$ group & SCI group & $\mathrm{P}$ value \\
\hline Total dyadic adjustment scalef & $69.65 \pm 18.28$ & $70.06 \pm 20.88$ & $>0.05$ \\
\hline Husband $(n=30)$ & $72.25 \pm 17.45$ & $71.24 \pm 21.51$ & $>0.05$ \\
\hline Wife $(n=30)$ & $67.05 \pm 19.66$ & $68.88 \pm 20.82$ & $>0.05$ \\
\hline Dyadic consensus subscale & $47.90 \pm 13.71$ & $50.41 \pm 14.30$ & $>0.05$ \\
\hline Husband $(n=30)$ & $49.90 \pm 12.59$ & $51.18 \pm 15.85$ & $>0.05$ \\
\hline Wife $(n=30)$ & $45.90 \pm 14.80$ & $49.65 \pm 13.02$ & $>0.05$ \\
\hline Dyadic cohesion subscalet & $7.65 \pm 2.70$ & $9.62 \pm 2.73$ & 0.003 \\
\hline Husband $(n=30)$ & $7.65 \pm 2.66$ & $9.53 \pm 2.48$ & 0.034 \\
\hline Wife $(n=30)$ & $7.65 \pm 2.82$ & $9.71 \pm 3.04$ & 0.040 \\
\hline Affectional expression subscale & $14.10 \pm 4.27$ & $10.03 \pm 6.22$ & 0.002 \\
\hline Husband $(n=30)$ & $14.70 \pm 4.46$ & $10.53 \pm 5.23$ & 0.013 \\
\hline Wife $(n=30)$ & $13.50 \pm 4.10$ & $9.53 \pm 7.20$ & $>0.05$ \\
\hline
\end{tabular}

* Able-bodied couples. $\uparrow$ Spinal cord injured couples. $\$$ No difference between husbands and wives in both AB group $(P>0.05)$ and SCI group $(P>0.05)$ for total dyadic adjustment scale, dyadic consensus subscale, dyadic cohesion subscale, and affectional expression subscale

Table 4 Marital agendas protocols in $\mathrm{AB}^{*}$ and $\mathrm{SCI} \dagger$ couples

\begin{tabular}{lccc}
\hline Scale & AB group & SCI group & P value \\
\hline Problem intensity score & $213.00 \pm 156.36$ & $280.00 \pm 173.89$ & $>0.05$ \\
Husband $(n=30)$ & $206.75 \pm 143.20$ & $265.90 \pm 164.62$ & $>0.05$ \\
Wife $(n=30)$ & $219.25 \pm 172.04$ & $294.15 \pm 186.71$ & $>0.05$ \\
\hline
\end{tabular}

* Able-bodied couples. $\uparrow$ Spinal cord injured couple. $\ddagger$ No difference between husbands and wives in both AB group $(P=0.942)$ and SCI group $(P=0.643)$ for problem intensity score 
husbands and wives in both AB group $(P>0.05)$ and SCI group $(P>0.05)$ for total dyadic adjustment scale, dyadic consensus subscale, dyadic cohesion subscale, and affectional expression subscale.

\section{Marital satisfaction}

In Marital Agendas Protocol, there was no significant difference in problem intensity score between the two groups (Table 4) and no difference between husbands and wives in both $\mathrm{AB}$ group $(P=0.942)$ and SCI group $(P=0.643)$ for problem intensity score. However, in the AB group, money was the most serious problem. Problems related with in-laws, as well as alcohol and drugs were the next serious problems (Table 5). In the SCI group, sex was the most serious problem; communication and recreation were the next serious problematic areas (Table 5). Looking into problem areas by sex, money was the number one problem for husbands among the AB couples, and problems related

Table 5 Problem intensity score according to problem areas of marriage

\begin{tabular}{lclc}
\hline Problem areas of marriage & Able-bodied group $(\mathrm{n}=30)$ & $\begin{array}{c}\text { Spinal cord injured group }(\mathrm{n}=30) \\
\text { Problem }\end{array}$ & intensity \\
Problem & score & Problem areas of marriage & 47.6 \\
Money & 32.3 & Sex & 40.3 \\
In-laws & 29.7 & Communication & 40.0 \\
Alcohol and drugs & 27.0 & Recreation & 33.2 \\
Communication & 23.1 & Money & 32.4 \\
Friends & 21.4 & In-laws & 30.3 \\
Recreation & 19.6 & Children & 27.9 \\
Children & 18.4 & Friends & 16.2 \\
Sex & 17.9 & Jealousy & 8.2 \\
Religion & 13.2 & Alcohol and drugs & 3.8 \\
Jealousy & 10.3 & Religion & \\
\hline
\end{tabular}

Table 6 Problem intensity score according to problem areas of marriage in able-bodied couples

\begin{tabular}{lclc}
\hline & $\begin{array}{c}\text { Husband }(\mathrm{n}=30) \\
\text { Problem areas of marriage }\end{array}$ & & $\begin{array}{c}\text { Wife } \\
\text { Problem }\end{array}$ \\
\hline Money & $\mathrm{n}=30)$ & Problem \\
In-laws & 33.5 & Intensity score & 31.5 \\
Alcohol and drugs & 28.0 & Money & 31.3 \\
Friends & 26.8 & Alcohol and drugs & 27.3 \\
Recreation & 22.0 & Communication & 26.5 \\
Communication & 21.5 & Friends & 20.8 \\
Sex & 19.7 & Children & 20.3 \\
Children & 17.3 & Sex & 18.5 \\
Religion & 16.5 & Recreation & 17.8 \\
Jealousy & 11.5 & Religion & 15.0 \\
\hline
\end{tabular}

Table 7 Problem intensity score according to problem areas of marriage in spinal cord injured couples

\begin{tabular}{lclc}
\hline \multicolumn{2}{c}{$\begin{array}{c}\text { Spinal cord injured } \\
\text { Problem areas of marriage }\end{array}$} & Problem $(\mathrm{n}=30)$ & Wife \\
Prtensity & score & Problem areas of marriage & Problem intensity score \\
\hline Sex & 51.8 & Sex & 43.5 \\
Communication & 44.7 & Recreation & 42.4 \\
Recreation & 37.6 & Friends & 37.1 \\
Money & 34.7 & In-laws & 36.5 \\
Children & 29.4 & Communication & 35.9 \\
In-laws & 28.2 & Money & 31.8 \\
Friends & 18.8 & Children & 31.2 \\
Jealousy & 11.2 & Jealousy & 21.2 \\
Religion & 7.6 & Alcohol and drugs & 14.7 \\
Alcohol and drugs & 1.8 & Religion & 0 \\
\hline
\end{tabular}


with in-laws was the most serious problem for wives (Table 6). In SCI couples, sex was the most serious problem for both husbands and wives (Table 7), and its problem intensity score was 51.8 for husbands and 43.5 for wives.

\section{Discussion}

An earlier analysis of the National SCI Database information concluded that in the first 3 years after injury, divorce was at least 2.3 times as frequent than would have been expected on the basis of US population statistics. ${ }^{2}$ It has been our impression that the marital life of chronic SCI couples with pre-injury marriages was unstable and unhappy when compared with that of able-bodied couples. However, according to our current study, the marital life of the chronic SCI couples was not noticeably unstable when compared with that of $\mathrm{AB}$ couples. In general, the marital relationship at the early stage of a spouse's SCI might be unstable and might have a higher divorce rate when compared with the control group. ${ }^{4,9}$ However, the marital relationship of chronic SCI couples who overcome this acute stage does not seem to be highly different from that of the control group.

A focal point in this study was that marital stability reported by wives in the patient group was significantly higher than that of the control group. This finding probably results partly from Korean cultural characteristics. Wives of SCI husbands seem to accept a cycle of change related to their husbands' disability as their fate. We thought that in Western countries, somewhat different results might be reported, and if the subjects of the patient group were SCI wives and their non-disabled husbands, results would be quite different from those of this study. Further studies about the life and marital satisfaction for SCI wives in pre-injured marriage are required. According to our literature review, ${ }^{10-12}$ Abrams concluded that there was no evidence that SCI has a devastating effect on marriages. Putting these reports and our current study result together, it seems clear that high levels of subjective quality of life and high life satisfaction are possible for SCI couples.

In pre-injury marital relationships, there were no significant differences in dyadic adjustment and marital satisfaction between SCI couples and AB couples. However, although SCI couples had more cohesive marital relationships, SCI husbands expressed less affection to their wives than $\mathrm{AB}$ husbands. The cohesive marital relationships of SCI couples reflect that most SCI husbands (22 SCI husbands, $73 \%$ ) are not employed, and the couples spend most of their time together at home. Therefore, dyadic cohesion in SCI couples was reported to be high. But, although there is a high dyadic cohesion among SCI couples, their affectional expression towards their wives was infrequent when compared with AB couples. Authors think that if the subjects were post-SCI married couples, husbands' affectional expression might be more frequent than this study. Generally, persons married after injury appear to be happier and are more often sexually active, more independent and more likely to be employed than their counterparts who married before injury. ${ }^{13}$

In this study, there was no significant discrepancy of the quality of marital life between SCI husbands and their non-disabled wives, suggesting a relatively healthier marital relationship than marriage with much discrepancy between spouses.

One of the most interesting facts in this study was the differing problematic areas in the marriages of $\mathrm{AB}$ couples and SCI couples. Subjects of this study were from relatively low income brackets in Korea and the most serious problem in $\mathrm{AB}$ couples was financial. The fact that problems relating to in-laws were the most serious problems among $\mathrm{AB}$ wives is an unexpected result of the study. In Korean society, problems related with in-laws seem a source of great stress. Contrary to the control group, sex was the most problematic area of marriage in chronic SCI couples; communication and recreation followed as the next serious areas in their marital life. Therefore, during rehabilitation strong emphasis should be placed on a sexual rehabilitation, more positive communication patterns, and encouragement of mutually enjoyable activities.

Several potentially serious methodological issues must be considered when interpreting the results of this study. Subjects of this study were couples who had marital relationships that permitted both husbands and wives to participate in the questionnaire study together. Divorced or separated couples were not included in this present study. In addition, the respondents of the questionnaire study may have hesitated in answering the questions frankly. In sensing that their responses could be released to their partners, the frankness of the respondents may have been suppressed. These two factors may be partly reflected in the higher quality of marital life results of this study. But the two factors mentioned above were common in both AB- and SCI couples, and the statistical comparison of the two groups in this study had a considerable significance.

In conclusion, the quality of marital life in chronic SCI couples is not highly different from that of ablebodied couples. It seems necessary that rehabilitation programs for SCI patients must provide informations about the altered physiology of sexual function among SCI patients, and the subsequent mutual adaptation to changed sexual function that is necessary among SCI couples.

\section{Acknowledgements}

Special thanks to Miss Jane Lee in Boston for her assistance in translation of manuscripts into English. 


\section{References}

1 Crewe NM, Krause JS. Marital relationships and spinal cord injury. Arch Phys Med Rehabil 1988; 69: 435-438.

2 Dijkers MP, Abela MB, Gans BM, Gordon WA. The aftermath of spinal cord injury. In: Stover SL, DeLisa JA, Whiteneck GG (eds). Spinal cord injury: clinical outcomes from the model systems. An Aspen Publication 1995, pp 199-210.

3 Stensman R. Adjustment to traumatic spinal cord injury. A longitudinal study of self-reported quality of life. Paraplegia 1994; 32: $416-422$.

4 DeVivo MJ, Fine PR. Spinal cord injury: its short-term impact on marital status. Arch Phys Med Rehabil 1985; 66: 501-504.

5 Booth A, Edward J. Marital Instability Scale. In: Filsinger E (ed). Marriage and family assessment: a sourcebook for family therapy. Beverly Hillsm 1983; pp 155-158.

6 Booth A, Johnson D, Edwards JN. Measuring marital instability. J Marriage Fam 1983; 45: 387-393.
7 Spanier GB. Measuring dyadic adjustment: new scales for assessing the quality of marriage and similar dyads. $J$ Marriage Fam 1976; 38: $15-23$.

8 Notarius CI, Vanzetti NA. The marital agendas protocol. In: Filsinger E (ed). Marriage and family assessment: a sourcebook for family therapy. Beverly Hillsm 1983, pp $72-74$.

9 Urey JR, Henggeler SW. Marital adjustment following spinal cord injury. Arch Phys Med Rehabil 1987; 68: 69-74.

10 Abrams KS. Impact on marriage of adult-onset paraplegia. Paraplegia 1981; 19: $253-259$

11 El Ghatit AZ, Hanson RW. Marriage and divorce after spinal cord injury. Arch Phys Med Rehabil 1976; 57: 470-472.

12 Pinkerton AC, Griffin ML. Rehabilitation outcomes in females with spinal cord injury: Follow-up study. Paraplegia 1983 21: $166-175$

13 Crew NM, Athelstan GT, Krumberger J. Spinal cord injury: a comparison of preinjury and postinjury marriages. Arch Phys Med Rehabil 1979; 60: $252-256$. 